\title{
Preface to Research on Role of Technology in Workforce Management
}

\author{
Manish Gupta \\ IBS Hyderabad \\ Hyderabad \\ India. \\ manish.gupta.research@gmail.com
}

\section{Jatin Pandey}

Indian Institute of Management

Indore

India.

\section{Jighyasu Gaur}

T A Pai Management Institute,

Manipal

India.

\section{Neharika Vohra}

Organizational Behaviour

Indian Institute of Management

Ahmedabad

India.

Technology has become omnipresent in our lives and workplace is no exception. Recent advancements in human resource management (HRM) and organizational behaviour (OB) are predominantly technology driven that require techno-savvy human resource managers (Lengnick-Hall \& Lengnick-Hall, 2018). In general, the quest for effective and efficient workforce management has led to embracing digitization (Berber et al., 2018). It does affect the several stages of a typical human resource process which includes stages such as recruitment, selection, performance appraisal, demand forecasting, supply forecasting, job description, job specification, job analysis, job evaluation, training and development, career planning and development, and succession planning among others (Tooranloo, et al., 2017). Technology is a double edged sword with potential to make or break organizations with major consequences for employees and employers.

We are experiencing the impact of Industry 4.0 on HR functions. For example, chat-bots are assisting in screening candidates (Sivathanu \& Pillai, 2018), analytics-powered employee demand and supply prediction (Sommers, 1999), and smart offices connected through cloud and social networks (Filos, 2008). Crowdsourcing is on a record spree, with Deloitte forecasting five billion people engaged in crowdsourcing projects by 2020 (Howe, 2006; Grewal-Carr \& Bates, 2016), performance appraisal of employees can be done using a mobile app (Samuel et al., 2014), and sophisticated human resource information systems (HRIS) manage all HR processes ranging from the simple ones such as leave management and salary slip generation to more complex processes such as succession planning (Nagendra \& Deshpande, 2014). Rapidly developing technology which is available to both employers as well as employees can become a source of sustained competitive advantage or a catalyst of 
ineffective utilization of organizational assets. This pervasiveness, peculiarity and potential of technology at workplace needs extensive exploration and examination.

Thus, the objectives of this special section are (1) to gain theoretical insights into the relationship between technology and employee level factors, (2) to capture the increasingly changing nature of workforce and its management, and (3) to examine role of external factors such as social, cultural, and market conditions among others in affecting the relationship between employee behaviour and technology.

Organizations want and would want the technology and the talent to work in tandem. Organizations thus need to use newer web-based technologies to attract these talented professionals. It has been observed that the firms have not been able to attract the best talent due to several reasons including the reach of information to the job aspirants. However, with the advent of web 2.0 technologies such as podcasts, blogs and online employee testimonials, the employers can communicate and attract the talent far easier than ever before. The first article, Talent Attraction through Online Recruitment Websites: Application of Web 2.0 Technologies, investigates the impact of web 2.0 technologies such as podcasts, blogs and online employee testimonials talent attraction. The findings show a positive impact of video podcasts and realistic employee testimonials (presented through third-party blogs) on job-seekers' perceived quality and credibility of the job advertisement. The add-on advantage of the web 2.0 technologies is increase in brand value of the employers. Technology thus becomes an important facilitator of the absorption of talent in today's team-based organizations. These teams now are now spread across geographical locations and Global Virtual Teams (GVTs) have become an indispensable part of organizations. Organizations are receiving projects from across the globe. To complete these projects, organizations need virtual teams that have members from different cultural backgrounds and time zones, may (or may not) meet inperson to take complex decisions. The major challenge for the organizations to make GVTs successful is engaging the employees who are not physically present. Employee engagement requires employees' cognitive, behavioural and physical state directed towards organizational outcomes. The second article, Drivers of Employee Engagement in Global Virtual Teams, conceptualizes five drivers of employee engagement namely cultural intelligence, communication (formal and informal), technology, trust, and individual maturity through interpretive analysis employees working in organizations that extensively use GVTs for achieving its strategic goals.

Technology also facilitates behaviours that are deviant to organizational norms and this particular aspect is studied in the third article. This article brings into light the supervisor who is an important stakeholder that nurtures the acquired talent in organizations. Supervisor plays a critical role in enhancing and deterring subordinate behaviours; the third article, Impact of Supervisors' Perceived Communication Style on Subordinate's PsyCap and Cyberloafing, shows how the passive, aggressive, and assertive communication styles of the supervisor affect the psychological capital (PsyCap) and cyber-loafing. Results from 680 full-time managerial employees show that supervisors assertive and aggressive communication styles impacted psychological capital which in turn impact cyber-loafing.

It is essential for organizations to ensure that the acquired talent is retained in the organization and allowed to grow. Information technology (IT) industry provides a knowledge-based working environment to its employees in terms of the flexibility for progression of career and management of family along with work. The second article investigates specifically for IT 
professionals how the fit/misfit impacts career satisfaction. Results of the fourth study, Expectations from Technology and Career Satisfaction: A Study among IT Professionals in India, show that the perceived fit as well as misfit between experienced and expected growth in career, work-life balance impacts career satisfaction.

We conceptualize today's organizations as talent repositories and based on the synthesis of these papers we propose technology-enhanced talent management for new age organizations. Initially, the use of technology is essential for attracting potential talent followed by a fit of selected talent and the job. Supportive supervisors and technology for virtual engagement can inhibit deviant behaviours and lead to a refined talent capital for an organization that bestows sustained competitive advantage. Figure 1 illustrates how organizations that are essentially talent repositories can be benefitted by the three technological forces.

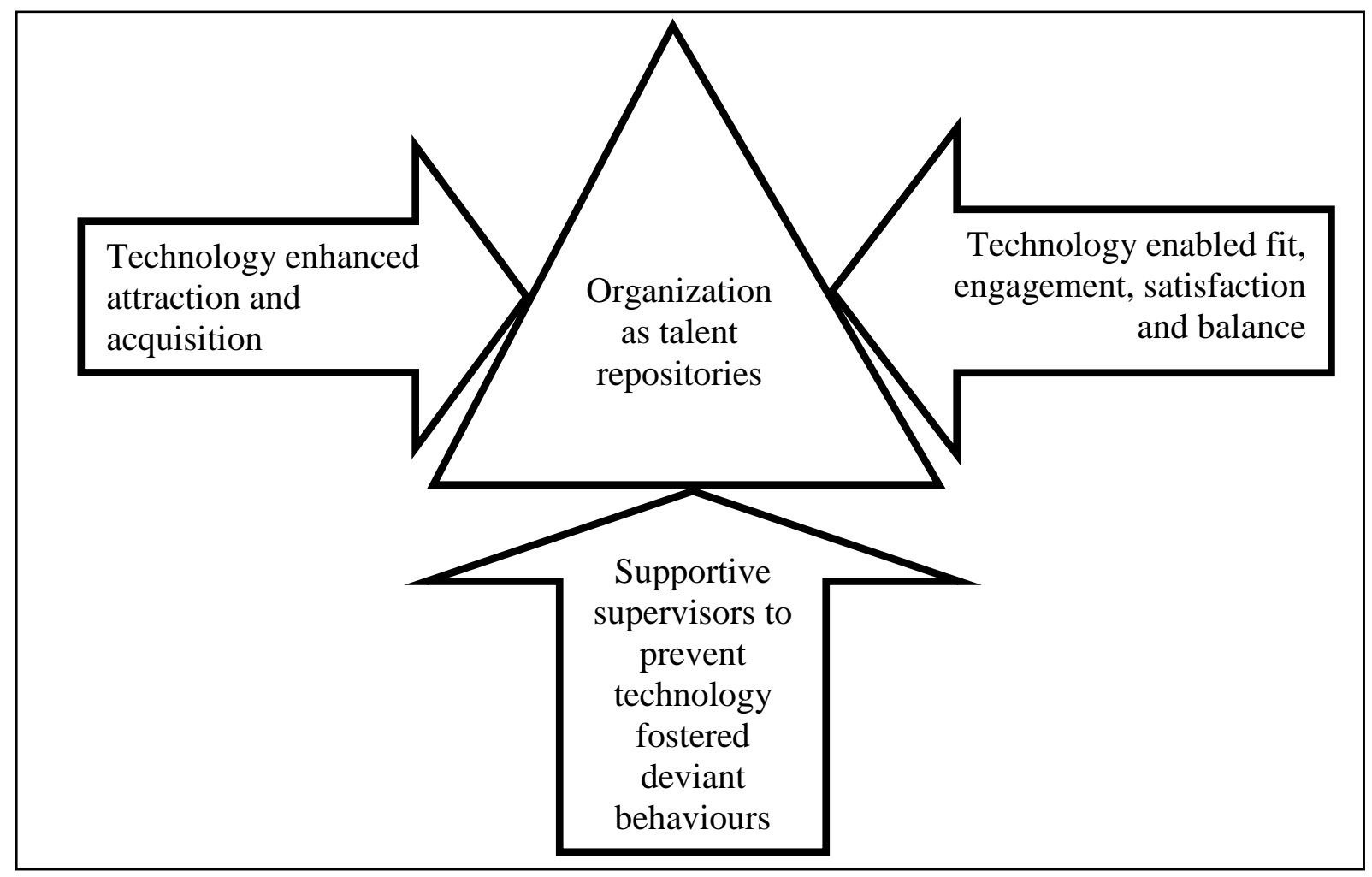

Figure 1: Organizations as talent repositories

The organizations can derive the aforesaid benefits (1) by technology-enabled attraction and acquisition, (2) through technology-enabled fit, engagement, satisfaction and balance between work and family life, and (3) through supportive existing talent in the organization in the form of supervisors who can prevent technology fostered deviant behaviours like cyber-loafing.

\section{Direction for Future Research}

Organizations are increasingly seen as talent repositories and technology is playing a vital role in recruiting, training, retaining, and assessing talent. It is essential that the future research focuses on identifying the issues, whether technological or technical, in making the data technology friendly. Once these concerns are identified, the research on addressing these issues would be required. Though this special section has taken the initiative of not only identifying three issues relating to technology enabled fit with the job attitudes, supervisor support, and technology enhanced attractions, the theme under investigation is still in its 
nascent stage. Thus, we urge the future studies to explore, capture, and examine the role of technology in managing a workforce at department, branch, subsidiary, organizational, country, and inter-country level. Moreover, studies comparing different contexts such as interbranch, inter-industry, cross-country would help researchers and practitioners understand the dynamics of the relationship between technological and HR variables in different situations.

\section{References}

Berber, N., Đorđević, B., \& Milanović, S. (2018). Electronic human resource management (eHRM): A new concept for digital age. Strategic Management, 23(2), 22-32.

Grewal-Carr, V., \& Bates, C. (2016). The three billion: Enterprise crowdsourcing and the growing fragmentation of work. Deloitte Consulting LLP, available at: https://www2.deloitte.com/content/dam/Deloitte/de/Documents/Innovation/us-consenterprise-crowdsourcing-and-growing-fragmentation-of-work\%20(3).pdf

Howe, J. (2006). The rise of crowdsourcing. Wired magazine, 14(6), 1-4.

Lengnick-Hall, M. L., \& Lengnick-Hall, C. A. (2018). Strategic management approach to technology-enabled HRM. In e-HRM (pp. 45-61). Routledge.

Nagendra, A., \& Deshpande, M. (2014). Human Resource Information Systems (HRIS) in HR planning and development in mid to large sized organizations. Procedia-Social and Behavioral Sciences, 133, 61-67.

Samuel, O. W., Omisore, M. O., \& Atajeromavwo, E. J. (2014). Online fuzzy based decision support system for human resource performance appraisal. Measurement, 55, 452-461.

Sivathanu, B., \& Pillai, R. (2018). Smart HR 4.0-how industry 4.0 is disrupting HR. Human Resource Management International Digest, 26(4), 7-11.

Somers, M. J. (1999). Application of two neural network paradigms to the study of voluntary employee turnover. Journal of Applied Psychology, 84(2), 177.

Tooranloo, H. S., Azadi, M. H., \& Sayyahpoor, A. (2017). Analyzing factors affecting implementation success of sustainable human resource management (SHRM) using a hybrid approach of FAHP and type-2 fuzzy DEMATEL. Journal of Cleaner Production, 162, 1252-1265.

Copyright: (c) 2019 Gupta, Pandey, Gaur \& Vohra. This is an open-access article distributed under the terms of the Creative Commons Attribution-NonCommercial 3.0 Australia License, which permits non-commercial use, distribution, and reproduction in any medium, provided the original author and AJIS are credited. 


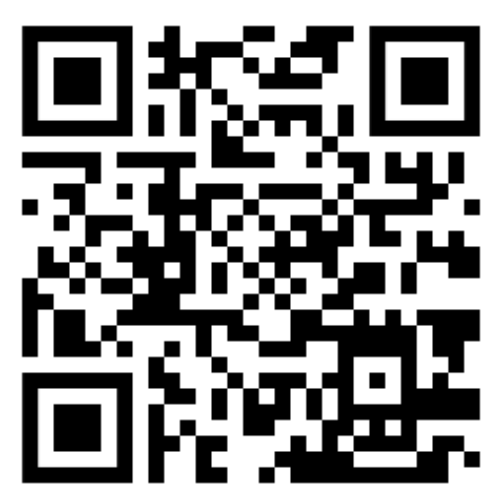

